\title{
Beyond Lamaze: Are We Missing the Key to Unlock Women's Potential?
}

\author{
Sangheetha Parthasarathy, DipHB(KGH)
}

\begin{abstract}
In this article, the author shares her birth stories and uses what she has learned to rethink childbirth education and her role as a childbirth educator. There is a bridge from knowledge to action. The thinking part of the brain is like the tip of an iceberg. While the subconscious is what drives many actions, childbirth education classes often talk to the conscious, rational part of our brain. What is the fundamental trick we are missing in childbirth education?
\end{abstract}

The Journal of Perinatal Education, 27(1), http://dx.doi.org/10.1891/1058-1243.27.1.6

Keywords: physiological birth, neocortical inhibition, childbirth education, politics of childbirth, laboring woman as a skillful agent

My name is Sangheetha. My husband and I belong to the classic Lamaze customer base. We are in our early 30 s, urban, educated, with busy careers - and would research and overanalyze most aspects of our lives, wanting a degree of control over it, to say the least. So when we found out we were pregnant (expected and "planned" of course), we did what most couples would do-ordered the infamous expectant parents book. It arrived, and I have to say-reading the first couple of pages sent my anxiety through the roof-it didn't read like a pregnancy book; more like an encyclopedia of everything that could potentially go wrong.

A friend of mine had recently given birth-at home, in the pool with a doula and a midwife. That idea was initially shocking to us-we couldn't do that, could we? My friend would then very calmly explain how women's bodies were innately capable of giving birth, and the medicalization of childbirth. It opened up a whole new world for me. I started to see feminism through the reproductive lens and what was at stake.

Of course, we attended childbirth education classes in the United Kingdom. It takes up a large part of your weekends during your final trimester. There was nothing democratic about it, of course-the free National Health Service (NHS) hospital classes wouldn't do for most middle-class (read middle- to high-income) couples. We had to get into one of those exclusive and pricey ones, so we could meet "other like-minded" couples_read, people who lived in your neighborhood, your kids would attend the same schools, classes, and so on. Childbirth classes in the United Kingdom have become more like a Tinder for middle-class couples than about education, but I digress. In addition, we also did Hypnobirthing, a water birth course and hired a doula, who was also a birth photographer. Safe to say, most weekends of my pregnancy saw us 
doing something birth-related. Knowledge is power, isn't it? The more information I had, the more books I read, the better prepared I would be.

My first planned home birth didn't end at home-we transferred to the hospital, it wasn't an emergency-blue-light situation either, my waters broke, there was meconium in the waters and we made the informed choice to transfer in. I watched the events unfold-and my mind was predicting the cascade of interventions that would follow, my daughter was born vaginally the next day, after an epidural and a few hours of augmentation.

A subsequent pregnancy and I had a textbook home birth. We were the classic second-time parents, essentially ignoring the pregnancy for as long as we could, running around with our full-time careers, and raising toddler. This time, I let go-any outcome would be fine with me, and it seemed to do the trick. That led me to question-are we missing a fundamental trick here?

And here is my larger challenge: has childbirth education reached the limits of its potential in its current format? I think so. Why? As childbirth educators, we are all aware that there is a bridge between knowledge and action. And that seems to be where the gap is. Here are some reasons:

\section{CHILDBIRTH EDUCATION TALKS TO THE CONSCIOUS, THINKING, COGNITIVE PART OF THE BRAIN}

Let's compare what we knew in the 60 s to what we know now. Today we have at our disposal a vast ocean of data and information, not just from biology but physiology, neurobiology, epigenetics, and psychoneuroimmunology (yes, it's a real discipline, google it). From a psychodynamic perspective, we know that only $5 \%$ of our behaviors come from the conscious part of the brain, the other $95 \%$ is the subconscious brain. All education classes focus on the "thinking" part of the brain, the 5\%. However, 95\% of our actions are influenced by the subconscious, which has been listening and imbibing cultural messages about the woman's body and childbirth for generations. And while knowledge is the start, it isn't necessarily sufficient to drive action.

\section{WHAT IS THE KEY TO UNDERSTANDING PHYSIOLOGICAL BIRTH PROCESS? NEOCORTICAL INHIBITION}

Dr. Michel Odent has perfected the art of conveying complex neuroscience and physiological concepts in
Has childbirth education reached the limits of its potential in its

\section{current format?}

ways that everyone can understand. So, I am paraphrasing, relaying from memory my recent conversation with him.

Nature has perfected a system, through millions of years to facilitate childbirth. To understand the birthing process, one must compare it to other physiological functions. Imagine a couple making love, in a preorgasmic state-one of the partners suddenly says, "what do you want for dinner later"-the physiological process of making love halts. Why? Because the neocortex, or the thinking brain, is stimulated. Similarly, a birthing woman, has one need-protection. Protection from all forms of neocortical stimulation during labour-through language, lights and being observed.

Isn't it ironic then that the birth world seems to be polarized into two camps-the medical camp that wants to "manage" labor and the so-called natural birth camp that wants to "coach," "educate," or "support" a woman? I see in a lot of forums that women are asking the question "What method did you use to have a natural labor-Bradley or Lamaze or something else?" How well does the thinking brain switch off and let go if the laboring woman or her partner is focused on remembering the way to breath, specific positions, or the myriad of other information she has been taught. Can an argument be made that neither group, the medical or natural, fully embraces the crucial role of neocortical inhibition during labor? More importantly, both groups promote the same fundamental thought - that significant support is needed for women to be able to give birth. In the world of childbirth, could it be that more preparation is not necessarily better?

\section{THE CUSTOMER IS CHANGING FAST, BUT NOT THE APPROACH}

Today's pregnant woman spends a lot of her pregnancy engaging the thinking, rational intellectual part of the brain. This is a fundamental shift in societal dynamics - partly due to the nature of our jobs and increase in education levels and partly the fact that we live in a data-driven, information overloaded world. As I write this, I realize this might play

\section{And while knowledge is the start, it isn't necessarily sufficient to} drive action. 
Towards the end of the pregnancy, the body's neocortical functions

slow down as a natural way of getting more in touch with the

more primal, intuitive part of the brain, so oxytocin (among other

hormones) is produced and labour starts when baby and mother

are ready. By providing "food for thought" in childbirth education

classes, are we impeding this process?

right into patriarchy, so it is important to phrase this correctly. Urban women today are increasingly successful in all different types of careers, and these careers involve huge amounts of neocortical activity. In addition, couples are also often spending a part of pregnancy-making decisions about school districts, moving/buying houses, financial decisions, and career decisions, all of which involve the thinking brain. Towards the end of the pregnancy, the body's neocortical functions slow down as a natural way of getting more in touch with the more primal, intuitive part of the brain, so oxytocin (among other hormones) is produced and labor starts when baby and mother are ready. By providing "food for thought" in childbirth education classes in those final weeks, are we impeding this process? What discussions are we having around timing, duration, and length of these sessions?

\section{MOST MODERN URBAN COUPLES HAVE NEVER WITNESSED A PHYSIOLOGICAL BIRTH, OR EVEN HEARD ABOUT IT}

I was in conversation with Liliana Lammers, a very seasoned London doula recently. We were talking about the role of birth partners. She mentioned one case of a husband, who was extraordinarily calm as his wife was laboring. He was quietly reading a newspaper in one corner of the room. Liliana found it quite unusual that this first-time dad knew exactly what to do; so she asked him if he had any previous experience with birth. Yes, he said, 1,500 births. The man grew up in a farm.

Liliana also talks about how pets at home just intuitively know how to be around a laboring woman-they are calm and unobtrusive. I was talking to a woman a few days ago, about pregnancy and her thoughts on it. I was hinting that

\section{The Positive Birth Movement, founded by Milli Hill in the UK is}

a global, grassroots organization purely focused on women in

communities coming together to share positive birth stories. she should consider childbirth education classes, and prefaced the conversation with what she thought about birth. She calmly responded saying it doesn't faze her, and that she had witnessed some quick, unhindered births growing up. That immediately gave so much positive energy, and I didn't want to then introduce a lot of thinking brain what-ifs. If she chose a care provider that she trusted, this is a woman that could birth instinctively, easily.

\section{PEER POWER}

Group classes filled with (mostly) first-time parents have one thing in common. They are all trying to learn to unlearn. However, what is the most powerful bridge from knowledge to action? Story telling. Peer stories. Positive birth stories from women who look like us, who talk like us, who feel like us - and my case, overthink like I do. The Positive Birth Movement (PBM) founded by Milli Hill in the United Kingdom is a global, grassroots organization purely focused on women in communities coming together to share positive birth stories.

Once, at a PBM meeting, a woman shared a story of laboring at home through the night, and then she had her mother take her firstborn out to the nursery (day care) in the morning. Her second one was born an hour later. I witnessed another woman, a secondtime mum, grappling with anxiety around her firstborn-who her toddler would be with during her second labor. This story quite quickly brought the mind-body connection to light. When the firstborn is sorted, sleeping, or with a trusted caregiver, the woman's body can "let go" and labor progresses quickly. This was a lot more powerful than me trying to draw the oxytocin-adrenalin seesaw on a whiteboard in a "one-to-many" setting.

\section{USING CREATIVE ART MEDIUM}

Media, more importantly the medium of comic humor, is a very, very underused technique. There is an Italian short film-Birth Like Sex, on YouTube (https://youtu.be/1ZG0T7xHy6A). It is a brilliant, comic take on how we've interfered with birth. It won the Artistic Direction Special Award at the Docscient International Scientific Film Festival 2014, "For the surprising capacity to question indestructible scientific paradigms using a paradoxical narrative trick. Brilliant and extremely effective."

What a brilliant way to bring home very complex textbook concepts of neocortex, oxytocin, 
and melatonin in a simple but effective way. What if we all started our classes with such videos?

\section{CULTURAL CONTEXT}

Here is where I think there is a big need for us to overlay cultural and local contexts to pedagogy. A one-size-fits-all approach is ineffective. I remember a story that a young woman told me once, about certified birth workers (childbirth educators, lactation consultants, doulas) in developing countries. They'd get employed by private hospitals to enhance their own brand-this then would lead to "policing" and editing what these professionals could say and provide. There is certainly a big need to refine governance processes. Should birthworkers only signpost in all contexts? What is the role of advocacy here? More importantly, how do we help couples build trust with their care providers so the woman feels protected and can "switch-off" during labor? This also brings to light the contentious issue of "informed consent." When in throes of labor and reduced neocortical activity, when it is appropriate to stimulate a woman's thinking by use of language to ask for consent? And is it really true rational consent? Shouldn't we instead focus on building trust with the care provider and her birth attendants throughout pregnancy?

Using these fundamental building blocks, I am now in the process of building a new framework to think about this topic — while knowledge is essential, how can we effectively build the bridge from knowledge to action?

\section{ACKNOWLEDGMENTS}

Thanks to Judith Lothian for inspiring a lively debate on this topic.

SANGHEETHA PARTHASARATHY is a Fellow of the University of Pennsylvania's Social Impact Strategy program. Her career spans three continents and straddles two lives-as a customer experience strategist, drawing heavily on her background in helping Fortune 50 companies and non-profit organizations design better interactions with their customers using technology (she has a masters in computer science), and the more intuitive part of her career as a doula, hypnobirthing instructor, and a birth trauma resolution therapist. She is passionate about bringing both parts of her career together to build capacity for a new generation of birth workers, especially in developing countries. She can be reached @worldoula on Twitter, Instagram, and YouTube. 